\title{
Examining Administrative Inputs for China's Public Emergency Response from the Perspective of System Costs
}

\author{
Zezhao LIU \\ School of Philosophy \& Public Administration, \\ Jiangsu Normal University \\ Xuzhou. China, 221116
}

\author{
Huijia WANG \\ The People's Procuratorate of Tongshan District \\ Xuzhou, China, 221100
}

\begin{abstract}
The cost and distribution of public emergency response is more addressed by government of various levels, and the origin of financial input system plays a vital role in exploring or resolving resources supply. This paper outlines the traits of China's financial expenditure operation in disaster handling with statistical data of specific cases. The results we obtained demonstrate that the cost of China's public emergency response is more limited from administrative inputs, while lacks social capital and the matched bottom-to-up internal reflections. The finding also shows that China's post-disaster reconstruction costs depend on a threshold ethics for operation that the social features is the core of resources distribution. Unlocking the box of administrative cost and increasing the common consciousness of social support would benefit the sustainable development of China's emergency management.
\end{abstract}

\section{Keywords-Public emergency; Managing cost; China; Policy}

\section{INTRODUCTION}

Public emergencies would usually cause or may cause heavy casualties, property losses, ecological damage and serious social harm. Generally, public emergencies can be divided into four categories, ie. natural disasters, catastrophic accidents, public health and social security incidents, which differs both in evolution mechanism as well as the actual response pathway [1]. China is one of the most frequent disaster-ridden nations in the world. Due to the exposure of natural disasters, work accidents, social security incidents and public events, death or heavy injures have taken place in terms of more than 1 million people since the $21^{\text {st }}$ century.

Public emergencies response is closely connected to the public safety delivery, therefore, the government participation in handling emergencies serves an unshakable obligation. The solution of emergencies always have to pay series of costs, and the administrative cost so as to safeguard the public life and property need to be enlightened around many aspects like the human, material, financial and other social resources. Not only the direct economic costs ,but also the indirect costs for the disaster discovery in the future time would have an impact on the whole society. Based on the Theory of Life Cycle [2], costs from public emergencies linked with many fields as in prevention, response and recovery. Compared with developed countries , China's disaster relief expenditure share is still low (about $0.3 \%$ ), while in this field Japan's disaster relief

This research is Funded by the Humanities and Social Science Program of Jiangsu Normal University (No.18XWRS002). spending accounts for $5 \%$ for the annual budget expenditure. Thus, it is significant to explore the administrative cost in the public emergency response facing especially the China transition economy.

\section{CHIEF ISSUES FOR EMERGENCY MANAGING COSTS}

\section{A. Non-permanence for the response}

Local Practice shows that the reason why public emergencies caused great damage is that it may not be aware of the importance of risk prevention, let alone the necessary inputs to prevent. According to China's Budge Law (2014), the budget in all levels of government would be the level expenditures of about $1 \%-3 \%$ reserve fund, while in reality many local governments are reluctant to take inputs without setting or lower than $1 \%$ of reserve fund concerning economic development. Some public events particularly those major social incidents like civil group accidents as a matter of fact can be better avoided if proper preventive measures and corresponding resources arrangement were better achieved. Inadequate cost of risk prevention would not reduce costs but increase the uncertainties.

From China's emergency response experiences, it can be found a phenomenon that unless the sudden public incidents occurred, the decision-making authority usually announced to establish a temporary headquarters. The attention of main political decision-makers plays a key role in the emergency response process. After the emergency strikes, the specific political leader may issue instructions to relief framework to ensure stability. Notably, the impromptu instruction will occupy the priority in the process of emergency handling, even if the instruction does not fully abide by the routine procedures. As aforementioned noted, the function of the temporary headquarter is not permanent although it may have an advantage with unified leadership, supervision and administrative performance. Once official disposal of these emergencies completely, the preset revocation of resource dissolution took effects and the administrators return to their original units. It Shows that there lacks the full establishment of a permanent organ for the emergency management as well as coordination. In contrast, some western countries like the U.S and Canada, have set up special handling agency responsible for public emergency simulation 
exercise, and when the emergency occurred it would rapidly assume the response and crisis handling task [3]. The set up of this temporary governing body in China is not conductive to deal with the accumulation of sound experience in public emergency, but also draw off the sunk costs of redundancies resulting in inevitably increased management costs for the administration.

\section{B. Administrative monopoly}

Public emergency management as a category of public goods to some degree, there is a large extent of existence concerning government monopoly, either resource inputs or internal financial maintenance. After China's 5/12 Wenchuan Earthquake devastating southwestern part of the country, the wide range of relief donations were converged, about 76,212 billion yuan(the donations from 65 billion yuan and equivalent material 11.4 billion yuan) were spent or expended through public channels.

TABLE I 5/12 Wenchuan Earthquake Donations

\begin{tabular}{|c|c|c|}
\hline Three ways of charitable donations & Amount & Percentage \\
\hline $\begin{array}{c}\text { Government } \\
\text { public offering }\end{array}$ & 37.9 billion & $58 \%$ \\
\hline $\begin{array}{c}\text { China Charity Foundation, and local } \\
\text { China Red Cross Society, China } \\
\text { Charity Federation }\end{array}$ & 19.9 billion & $31 \%$ \\
\hline Accillion & $11 \%$ \\
\hline
\end{tabular}

According to the published academic research from the Tsinghua University, contributions of above-mentioned three ways, all directly or indirectly originated from administrative sectors. The government steer the donations including CPC special membership dues, provincial government funds as well as the special earthquake relief accounts from the Civil Affairs Ministry. Flow of local Red Cross, Charity Foundation, and local public collecting donations, the fund took its own arrangements for public organizations to use. As the report of sample survey from Tshinghua University, most of these contributions were applied though government departments. This makes the earthquake grants form an allocation gap without effective supervision, which could bring about disadvantageous results over its spending. The relief funds not only result in administrative monopolies in the cost of waste and corruption, but also could conducive to the ineffective disaster relief work.

\section{Imperfect relief supporting system}

Public emergency needs resources of personnel, equipment, capital and other necessary inputs, many of these relief supplies are not "one-time use". Take 5/12 wenchuan earthquake as a case, the disaster consumes mobility tents around 440,000 and other millions of relief materials. Thus the equipment in the disaster relief played a vital role in public emergency, and the solution of equipment is faced with the "choice", for it often concerns about the collection and effective use of relief supplies. Although China promulgated the recovery of relief materials to the provisional level, the management performance as well as monitoring process still faces a number of tough issues [4]. Many materials ought to be recycled, such as tents, prefabricated housing, medical and power generation equipment. Some relief work could be reoccupied, and some may become free maintenance waste when the afterwards disaster comes. Inevitably it needs to repurchase of relief supplies, not only linked with a waste of social utility but also affects the quality of relief and makes the sudden increase in administrative costs of public events.

\section{PATHWAYS OF REDUCING COSTS OF EMERGENCY}

\section{A. To strengthen the prevention inputs}

As the Theory of New Public Management (NPM), the management objective for the public sectors is to "spend a small amount of money to prevent rather than a lot of money to treat'[6]. From China's local practice, the view of mild prevention in public emergency response prevails in more administrators, which is less beneficial to emergency management. For this aspect, it may put forward some pointed measures.

Firstly, the government may enter into service contracts with insurance companies to make up fund inadequacy and it has sound feasible practice. Catastrophe insurance claims abroad generally account for $30 \%-40 \%$ of national disaster losses, while in China this proportion is less than $1 \%$. In the 5/12/2008 Wenchuan Earthquake, the direct economic loss was 845.1 billion yuan but the external business insurance only occupy more than 2 billion yuan. In contrast, more developed countries like the US. have established and continuously improved various catastrophe insurance models to cope with such catastrophes, giving full play to the role of insurance in disaster relief. Since the year 2008, China Insurance Regulatory Commission issued the latest snowstorm insurance payments statistics, which ensures that the major insurance companies in the frozen snow disaster would offer prepaid claims and national compensation figure will be more than one billion yuan each year. This practice could be a progress toward external insurance participation besides government efforts.

Secondly, it ought to strengthen the awareness of prevention in the groups of local officials. Necessary training for emergency response capacity is quite needed and should enhance its coping ability in crisis. Financial inputs in emergency management generally ought to run through the whole process of pre-event, in-event and post-event. Existing relief expenditure should move forward the disposed funds and increase the proportion of early warning expenditure. The increment of relief should also put on the dominant proportion of early warning expenditure so as to transfer the relief function of the whole finance from passive relief to active prevention.

Thirdly, to foster public consciousness thought many channels. The public is the bearer of emergencies, to prevent and handle unexpected incidents is free of wide participation. If the public in the face of emergency can be effectively assisted, prevention is not only conductive to the practical settlement, but also to reduce government costs. It is necessary to integrate multiple funds dispersed in various government departments and change the situation of scattered, disordered and self-governing distribution. In the process of optimizing emergency functions, resources should be integrated, 
standardized and coordinated for the sharing of critical information. When the emergencies can quickly put into rescue work, it can avoid duplication caused by waste cost. Also, to improve monitoring, forecasting and rapid response systems in disaster relief is cost conductive to enhance professional supply of disaster relief materials.

\section{B. To enhance multiple participation}

Practices in the developed countries show that in response to sudden public events, enterprise participation could not only make full use of social capital but also relieve the financial burden in public agencies. As can be seen from the Fig. 1 that with a growing trend for natural disasters in China, the economic spending more increased during the past few years (2010-2017), but compared to the national disaster relief expenditures China's disaster relief expenditure ratio is still low. Therefore, to improve the puts for the disaster relief spending and achieve cash diversity, is an inevitable tendency in the future.

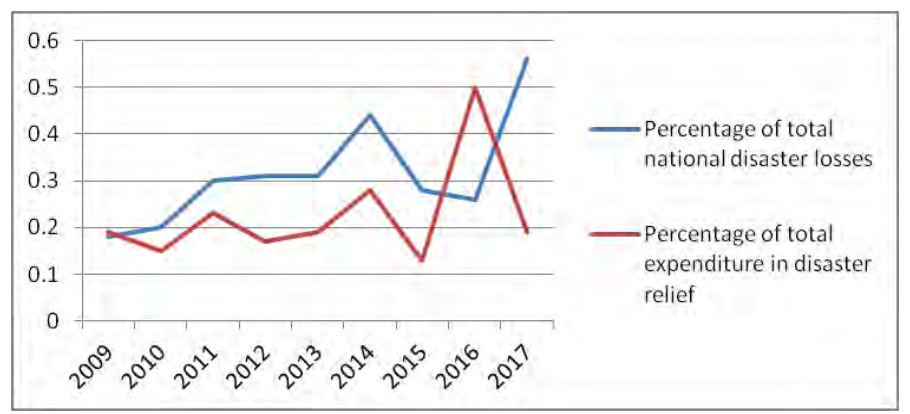

Fig. 1 The Inputs of Expenditure in Natural Disaster Relief (Unit: Billion, \%)

$$
\text { Note: adapted from the China Statistical Yearbook (2010-2017) }
$$

For example, the United States actively introduce flood relief to the insurance companies, while the local government are encouraged to purchase services for impelling market competition as to increase fund support. Assuming the land use and topography factors, it is often subjected to floods, wind, hail, cold, drought and other seriously disasters hurting the local agriculture. The government is very anxious to see this situation but occupy limited financial resources to solve the problem. After deliberations, the government has decided to cooperate with insurance company by investing insurance share for the local grain crops, while the insurance company carries on the appraisal by an insurance clause to compensate. The game's best equilibrium is that cooperation is a win-win situation. But the market in the reality is not omnipotent, corporate objectives is to pursue economic interests although social responsibility will not give up. Therefore, enterprise participation in public emergency response ought to be guided by the government. The government ensures participating enterprises the necessary qualifications to public emergencies and it has sufficient strength to help the former to jointly respond. At the same time, the government should provide the guidance for enterprises to participate in the effective way and make provisions for the scope of participation. Additionally, the government acts for companies to conduct the necessary oversight to ensure smooth settlement of fund organization.

In a study about SARS of a national telephone survey conducted by Gross Telegram over the mobilization of SARS prevention work, the highest rate is attributed to concentrated electoral units, governmental institutions and the lowest selection rate is attributed to non-governmental organizations. This result reflects a dilemma in China organization participation on public emergency and worth to rethink the practical situation. As matter of fact, in " $5 / 12 / 2008$ " worldshaking Wenchuan Earthquake, China's non-governmental organizations(NGO) quickly joined the rescue work, showing a strong ability to resource allocation. In response to public emergencies, the authority may grant certain rights to NGOs, which is beneficial to country's democracy among social institutions but also reduce the government's emergency spending. Specifically, the government should give NGOs an independence and certain autonomy to some extent for feasible coping, particularly on the autonomy of use of funds. The establishment of regular NGO monitoring mechanisms to prevent emergency enlargement may become a place of interest transactions.

\section{To improve the management system of relief materials}

Emergency resources are an important part of emergency rescue capability assessment. In case of an emergency, a large number of personnel, equipment and supplies are critically needed. Without adequate equipment and relief supplies (such as fire fighting equipment, personal protective equipment, leak cleaning equipment, etc.), even well-trained emergency rescue teams cannot mitigate emergencies on an ideal bases. Thus, in addition to a flexible and efficient response capability, a strong material backing or the so-called disaster relief is a quiet necessity. Improving the recovery of relief materials management system is not only conductive to protecting the property of the great public, but also reduce duplication purchase as well as cost savings. Therefore, facing practical dilemmas China ought to put disaster relief materials into reusable parts for recycling. Future disaster situations are situated over more timely relief, as will increase disaster relief and take the effects for the community to save fund among the emergency response system. According to the different characteristics of the implementation of relief materials recovery responsibility is specifically responsible for the implementation of the relief materials. Again, the use of relief and recovery supplies to conduct public notification might accept supervision by the great masses, leading to good maintenance of relief supplies.

\section{Cooperation network building}

Cooperation among governments at all levels of the network include the central government, local governments, inter-governments and non-peer collaboration among public sectors. Take the Public emergency response to infectious diseases as a case, in particular, the statutory administrative jurisdiction is often not a single area resolved, which requires the joint efforts of various government jurisdictions. These efforts and actions made the relationship gradually evolved from the original cooperation system to a wide network for coordination [5]. According to the provision of the State Council, it calls on its counterparts in support of such seriously devastating disasters as earthquake, particularly strengthen assistance in disaster restoration, reconstruction, manufacturing recovery and to provide economic cooperation as well as technical guidance[6]. Through intergovernmental 
cooperation, it gives full play to strengths from every social parts and avoid power diverge conductive to reduce the cost of government in the implementation capacity of emergencies.

At present, China is changing from the traditional planned economy to socialists market economic system during the transition period. With the establishment and improvement of the market economy, the socialist legal system will constantly be improved and the situation of public emergency will be more uncertain and sophisticated at home. The political, economic, legal system, resources such as environmental capacity would be cast constraints, and the impact of public emergency and disposal of its effects could increase the difficulty[7]. Therefore, it ought to face the tough situation and to enhance comprehensive capacity for the public sectors, carefully summing up past experiences while working with the international community for effective cooperation, especially cost reduction measures, and continue to improve the response to the theoretical basis of public emergencies.

\section{CONCLUSION}

This paper has sought to interpret the very significance of public emergency handling by analyzing administrative costs in China. In essence, the core of public emergency response is how to ensure system resources distribution before and after an emergency through cutting unnecessary costs. The operation of China's financial expenditure policy in disasters regrettably limited more from the government inputs, while lacks social capital as well as bottom-to-up reflections. Coping with a massive public emergency, particularly a disaster, is more achieved by steering the massive mobilization within the administrative system and political intervention. The wider its social influence, the greater the response costs being used. This indicates that China's administrative costs in handling emergency are highly sensitive to the traits of the incidence for its social significance and correspondingly increase the government pressure.

As for the change in the new era, the establishment of the emergency costs distribution system in the society needs to be addressed and it also ought to conduct the effective efforts about the inter-governmental relations in mutual coordination response. Consequently, it is quite urgent to reconstruct a more transparent and normative connections between China's cost assessment at the administrative level and emergency management mechanism. Eliminating input deficiency from social resources supply will to some extent help enhance a stable and sustainable development of the public emergency response system.

\section{REFERENCES}

[1] Hongchun, H. \& Yinghua, S. "Research on the Construction and Improvement to the Emergency Response Mechanism in Public Emergencies. Information Engineering and Applications". Springer Berlin Heidelberg. 2012.

[2] Han, J. , Zhang, P. , \& Song, Y. . "The Construction of Emergency Management Whole Process Model Based on the Emergency Life-Cycle: Wenchuan Case Study". Technology for Education and Learning. Springer Berlin Heidelberg. 2012.

[3] Li-Hong, L. U. \& Kao-Ding. "The enlightenment of public emergencies management on china from developed countries". Journal of Chinese Peoples Armed Police Force Academy. 2008. (In Chinese).

[4] Barzelay, M. "The New Public Management". University of California Press, US. 2010

[5] Leitmann, J. "Partnership Systems to Manage Post-disaster Recovery. Public Management as Corporate Social Responsibility". Springer International Publishing. 2015

[6] Xu, J. , \& Lu, Y. "A comparative study on the national counterpart aid model for post-disaster recovery and reconstruction: 2008 wenchuan earthquake as a case". Disaster Prevention \& Management, 22(1), pp.75-93. 2013.

[7] Cigler, BA. "Mainstreaming emergency management into public administration". Public Administration Review, 69(6), 2010, pp.11721176. 